\title{
Concepções de aprendizagem na formação inicial de professores e na docência
}

\section{Learning concepts in the initial training of teachers and in teaching}

\author{
Denise Dalpiaz Antunes*, Ortenila Sopelsa** \\ *Universidade Federal de Pelotas, ** UNOESC
}

\begin{abstract}
Resumo
A ação educativa embasa concepções de aprendizagem, pela qual o educador as revela nas práticas pedagógicas diariamente, na sala de aula, em cada contexto educativo. Nisso, este texto, resultado de pesquisa, num projeto de ensino na preparação à docência. Primeiramente, os alunos, graduandos, respondem como acreditam que os alunos aprendem. Outros dados foram coletados pelos mesmos alunos, são sistematizados qualitativamente, de modo reflexivo confrontando com teóricos. Os resultados indicam grande divergência teórica, quanto aos conceitos de aprendizagem, sinalizando, que uma grande maioria de respostas imbricam aprendizagem com ensino, atrelando resultados positivos do processo de aprendizagem às metodologias utilizadas pelos professores.

Palavras chave: aprendizagem, concepções do aprender, projeto de ensino, formação de professores, docência
\end{abstract}

\begin{abstract}
The educational action substantiates learning concepts by which the educator reveals them in the pedagogical practices, daily, in the classroom, in each educational context. This text is the result of a research of a teaching project on the preparation for teaching. First, the university students answer how they believe students learn. Other data were collected by the same students and were systematized qualitatively and reflexively collating with theorists. The results indicate a great theoretical divergence regarding the leaning concepts, highlighting that the great majority of answers connects learning and teaching, linking positive results of the learning process to the methodologies used by teachers.
\end{abstract}

Keywords: learning, conceptions of learning, teaching project, training of teachers, teaching

As práticas pedagógicas estão sustentadas pelas concepções de aprendizagem. Ou seja, na essência da ação pedagógica de cada professor está imbricada suas concepções de ser humano, de aprendizagem e de ensino consequentemente, as quais foram internalizadas ainda na infância, nas primeiras inter-relações educativas. Essas, se confirmam ou não na formação inicial do ser professor, podendo sim, serem reconstruídas em ações reflexivas, desde o início da formação ou ainda ao longo da formação continuada.

Aprender é processo na vida do ser humano; significa concentrar conceitos e normas específicas de modo a modificar ideias anteriormente concebidas, independente do momento do desenvolvimento pessoal. Processo esse, que se estabelece no convívio social, em contextos históricos e significativos para cada aluno (VYGOTSKY, 2002). Nisso, o professor deve buscar contextualizar o conteúdo com vistas às vivências dos indivíduos (MORIN, 2011). Apontando e intervindo em sua reponsabilidade de ensino, diretamente no nível de aprendizagem do aluno, na sala de aula (FREIRE, 1996). Tudo isto construtivamente, de modo a auxiliar o estudante a construir sua aprendizagem, desde que respeitada suas características, o tempo e o espaço de cada aprendizagem, na experiência de vida, inserido na cultura. "A mobilidade, a imigração, a miscigenação racial e o aumento das diferenças sociais, levam a que os alunos, precisamente na escola básica, de forma muito relevante (e muito mais que antigamente) se diferenciam nos seus conhecimentos prévios" (SPITZER, 2007, p.344).

Nesse mesmo sentido, sabe-se que a aprendizagem, seja do aluno em formação inicial para a docência, ou além dessa, a aprendizagem da/na docência do professor, deve se configurar numa proposta construtiva, de modo a sustentar que a "aprendizagem se constitui por meio de mediações, orientações, experiências e ações" (SOPELSA, GAZZÓLA, DETONI, 2009, p.1425). Para tanto, Nóvoa (1995 a, p, 25), salienta que a aprendizagem docente "não se constrói por acumulação (de cursos, de conhecimentos ou de técnicas), mas, sim através de uma trabalho de reflexibilidade crítica sobre as práticas e de (re)construção permanente de uma identidade pessoal".

Numa maior abrangência, o processo do aprender precisa estar integrado com as várias dimensões da vida humana, seja ela, física, psíquica, emocional, moral, biológica. São estas dimensões complexas, dentro de um contexto sociocultural. Nisso, o educador precisa estar atento ao "pensamento complexo, ecologizado, capaz de relacionar, contextualizar e religar diferentes saberes ou dimensões da vida" (MORIN, 2011, p.13).

Nisso ressalta Sopelsa (2000, p. 81) que "se analisarmos o fracasso que existe no processo ensinoaprendizagem, percebemos que ele acontece pela falta de um trabalho que reflita sobre a realidade existente em cada unidade escolar", além do conhecimento de outras dimensões da vida do ser humano. A mesma autora, também afirma que é necessário superar essas limitações de currículo e instrumentalizar os alunos a realizarem eles mesmos, uma leitura de mundo com interpretação do real concreto. 
Nesse sentido, Freire (1996) adverte que são necessários vários saberes à prática docente, entre eles, a exigência do respeito aos saberes dos educandos, com um olhar atento às necessidades de cada aluno, bem como a reflexão crítica sobre a prática educativa. Por isso, a necessidade da constante ação-reflexão-ação, seja na formação inicial com situações da docência para a docência, mas especialmente na formação continuada do educador a partir de sua prática diária, com vista a renovadas propostas pedagógicas. "[...]o professor é alguém que sabe alguma coisa e cuja função consiste em transmitir esse saber a outros, é importante observar como e onde se desenvolvem os saberes docentes" (SOPELSA, GAZZÓLA, DETONI, 2009, p.1419).

Sobretudo, "[...] se ignoramos as necessidades da criança e os incentivos que são eficazes para colocá-la em ação, nunca seremos capazes de entender seu avanço de um estágio para outro, porque todo o avanço está conectado com uma mudança acentuada nas motivações, tendências e incentivos" (VYGOTSKY, 2002, p. 121122). Entenda-se esse avanço por aprendizagens que só se efetivam se forem significativas para o indivíduo, se tiverem relação com suas metas e desejos pessoais. Por isso, tão imprescindível são propostas teóricometodológicas que indiquem situações de vivência de cada aluno em cada meio social.

É fundamental também, para um processo de ensino positivo, conforme afirma Sopelsa, Gazzóla, Detoni (2009, p. 1420) "[...] considerar a história de vida do aluno e a do professor no processo de ensinar e aprender. A presença física do aluno em sala de aula está imbricada na cultura, nos conflitos, desejos e ideais construídos no seu contexto social". Contudo, a constituição dos saberes docentes se efetivam no dia a dia da profissionalidade, ou melhor, os saberes dos professores, construído na docência, antes ainda na formação inicial, ou ainda no contexto sociocultural de cada um, também estão presentes na sala de aula, especialmente suas aprendizagens e concepções que sempre revelam a prática pedagógica, com suas escolhas metodológicas, além das propostas didáticas e curriculares. Ou seja, "o processo educativo é trilateralmente ativo: o aluno, o professor e o meio existente entre eles são ativos" (VYGOTSKY, 2003. p.79).

Ainda no sentido dos saberes docentes, enfatiza-se mais uma vez a construção continua que acontece no exercício diário do ser professor. Não obstante, Tardif (2005) afirma que a relação dos docentes com os saberes não se reduz a uma função de transmissão dos conhecimentos já constituídos. Ou melhor, sua ação educativa, integra-se de diferentes saberes, todos estes construídos no contexto social do professor.

Pode-se também destacar que "o saber docente como um saber plural, é formado pelo amálgama, mais ou menos coerente, de saberes oriundos da formação profissional e de saberes disciplinares, curriculares e experiências" (SOPELSA, GAZZÓLA, DETONI, 2009, p. 1419).

No entanto, ao saber que as aprendizagens docentes, vão se transformando e se efetivando no dia a dia da docência, "o pensar na formação docente deveria partir de um projeto único que englobasse a formação inicial e a contínua, em um processo duplo, de auto formação que tem seu princípio na reelaboração constante dos saberes utilizados na prática" (SOPELSA, GAZZÓLA, DETONI, 2009, p.1423).

Sabe-se que muitas vezes, o conhecimento do professor "[...] vem geralmente de uma aprendizagem por conta própria e isso deixa os professores entregues a si próprios [...] cada professor se considera único nas suas relações com os alunos, pois é bem "ele" que entra em relação com eles". (TARDIF, LESSARD, 2011, p. 90). Mas, contudo, para que essa relação seja respeitosa no sentido de proporcionar processos de ensino e de aprendizagem constante para ambos, enfatiza-se mais uma vez, que é imprescindível que da formação inicial à formação continua, a prática educativa seja o principal contexto de questionamentos e reflexões, com vistas a renovadas aprendizagens a qualquer tempo de vida, no desenvolvimento pessoal em cada ser humano.

\section{A investigação}

A partir destas concepções iniciais, esse estudo investigativo é resultado de pesquisa qualitativa, dentro de um projeto de ensino que está configurado em uma proposta reflexiva da docência, na docência e para a docência e suas principais ações pedagógicas. Sendo assim, a proposta acontece durante a formação inicial de professores, nos cursos de licenciatura e pedagogia, especialmente nas disciplinas que tem como enfoque as teorias e práticas pedagógicas, em duas universidades no sul do Brasil, com sentido de intuir a novas propostas do ensinar, pelas quais possa ser vislumbrado o aprender em qualquer etapa da vida humana, indubitavelmente de modo a respeitar cada ser humano em suas possibilidades, necessidades e potencialidades. Tardif (2012, p. 22-23) alerta para a necessidade de pensar/repensar a formação de professores "levando em conta os saberes dos professores e as realidades específicas de seu trabalho cotidiano. [..] uma nova articulação e um novo equilíbrio entre os conhecimentos produzidos pela universidade e os saberes desenvolvidos pelos professores".

Melhor explicitado, ainda no início do semestre letivo os alunos são questionados acerca de: como acreditavam que os alunos aprendem? Estes devem escrever sua resposta ao questionamento, pela qual indicam sua concepção inicial de ser humano, de aprendizagem. Em seguida, e após a explanação individual para a turma de colegas e professor, os mesmos alunos são convidados a refletirem sobre os conceitos apresentados, justificandoos e apontando às práticas que esses conceitos, fundamentam. Estas escritas, estes textos dos alunos, são guardados pelo professor, que ao final da disciplina os devolve para os alunos, de modo que os mesmos devem reler o que escreveram e refletir sobre as concepções iniciais, especificamente, se houve ou não alguma mudança, no que concerne aos conceitos iniciais e a disciplina que estão cursando, ou mesmo quando da análise dos dados apontados pelos professores da rede escolar que responderam a mesma questão.

Seguindo no processo de investigação, em seguida que o professor guarda os materiais dos alunos com as 
respostas pessoais, os mesmos alunos, são convidados a realizarem o mesmo questionamento, para professores que estejam atuando na escola, em práticas pedagógicas, na Educação Básica e no Ensino Superior: como acreditavam que os alunos aprendem? Cada aluno deve entrevistar seis professores, distribuindo-os nos diferentes níveis de ensino: Ensino Fundamental, Ensino Médio e Ensino Superior. As respostas da pesquisa de campo são analisadas e trianguladas (BARDIN, 2004) junto da turma, elencando as concepções dos professores entrevistados, de modo que novas reflexões possam ser efetivadas, contribuindo para a formação reflexiva pessoal, do grupo de alunos, futuros docentes.

Loughran (2009) alerta que de acordo com o modo de ensinar os alunos em uma pedagogia de formação de professores, poderão os futuros docentes, "[...] desenvolver-se enquanto profissionais de modo a irem além de uma simples aprendizagem sobre como 'ensinar' (p.20). O mesmo autor também destaca, que se deve trabalhar com a problematização do ensino, "para que haja uma atenção cuidadosa em relação aos pressupostos do raciocínio pedagógico tão importante no pensamento sobre o ensino" (LOUGHRAN, 2009, p. 20).

Nessa proposta de reflexão da/na ação educativa, pautada por concepções de aprendizagem, essencialmente, segue-se o processo de estudo investigativo, com a análise dos dados, a partir das respostas do questionamento inicial de como acredita-se que o aluno aprende. $\mathrm{O}$ estudo, nas duas universidades, indicou um entrelaçamento de conceitos e concepções de aprendizagem e de ser humano. Ainda que esse segundo, não seja objeto específico da pesquisa, destaca-se que a concepção de ser humano e seus processos de desenvolvimento, estão entrelaçados, ainda que "os processos de desenvolvimento não coincidem com os processos do aprendizado" (VYGOTSKY, 2002, p. 118).

Contudo, intui-se que, muitas vezes, a fala dos professores, diferem da práxis de cada um. Ou seja, o que o professor acredita conceber, não corresponde às propostas de ensino, sua metodologia e visão acerca do aprendizado do aluno.

Ainda assim, enfatiza-se mais uma vez, que essa prática reflexiva, na formação inicial poderá auxiliar os futuros docentes a compor de modo diversificado as práticas educativas, com um modelo pedagógico mais respeitador das características de cada aluno, principalmente atentando para os processos de desenvolvimento de cada indivíduo, onde esse se encontra, além de compreender as características de cada contexto cultural e utilizá-las como impulso para novas aprendizagens.

Quanto as respostas dos professores entrevistados, quanto a sua concepção de aprendizagem, a grande maioria aponta para metodologias, não importando o tempo de docência, nem diferindo da faixa etária que se encontra cada entrevistado. Ou seja, os professores atrelam os processos de aprendizagem ao processo de ensino, outrossim, delegando aos educadores a responsabilidade do aprender de seu aluno.

$\mathrm{Na}$ fala de alguns sujeitos esse entendimento:

- Cada aluno tem um modo de aprendizagem diferente e é preciso tentar em sala de aula o máximo de recursos que possam ser aproveitados por todos.
Então variar a metodologia, ajuda bastante... (P5EM)

- Minhas aulas são sempre diferentes e motivadoras, conto histórias relacionadas ao conteúdo... (P30EF) - Eu parto do meu esforço em oportunizar ao aluno criar sentido para o conteúdo. Consigo parcialmente, porque meu 'discurso' e minhas dinâmicas, evidentemente, não atingem a todos. (P56ES)

Muito embora, sabe-se que ao docente recai à necessidade de propor diferentes métodos de ensino, para atender a diversidade de alunos e de contextos com suas características culturais, também se alerta para a imprescindível conscientização de que o processo de aprendizagem é individual em cada ser humano, interferindo nesse, diferentes situações. Nesse contexto Bernardi (2014, p. 173) aponta que "se a criança não aprende, a culpa não é somente dela, com certeza a escola, a família e a sociedade possuem uma grande parcela desse fardo pesado de não aprendizagem". Especialmente quando se compreende que o processo de aprendizagem, embora esteja imbricado no desenvolvimento biológico, entre outros fatores, ainda assim, é no contexto social, no meio educativo, no espaço de relações interpessoais da sala de aula, que a aprendizagem se efetiva ou não, no caso de cada aluno, em qualquer idade, com dificuldades específicas.

Cabe destacar que a criança que apresenta problemas de aprendizagens, ou um adolescente, ou adulto aprendiz, especialmente no ambiente educacional institucionalizado, é uma pessoa "que precisa ser resgatada não somente na dimensão intelectual, mas, em todas as suas dimensões: orgânica, emocional e social" (BERNARDI, 2014, p. 173). Por isso, é um grande desafio do professor, estar em constante formação, numa educação continua que possa atender e acompanhar os diferentes alunos e suas especificidades que adentram a sala de aula, impreterivelmente, a cada dia na escola e em seu ambiente educativo.

Ao educador cabe trabalhar na zona de desenvolvimento proximal, onde o aluno aprende com a orientação do professor, (VYGOTSKY, 2002), sendo essa "[...] a distância entre o nível de desenvolvimento real, [...] e o nível de desenvolvimento potencial, determinado através da solução de problemas sob a orientação de um adulto ou em colaboração com companheiros mais capazes" (VYGOTSKY, 2002, p.112). Ou seja, a aprendizagem, processo intrínseco no desenvolvimento, acontece nas inter-relações e se internalizam nas intra-relações, ainda que "os processos de desenvolvimento não coincidem com os processos de aprendizagem" (VYGOTSKY, 2002, p. 118).

Outro ponto de reflexão nessa pesquisa, refere-se as respostas dos alunos em processo inicial de formação profissional docente, as quais não diferem muito das respostas dos professores entrevistados. Em sua grande maioria também atribuem ao sucesso do processo de aprendizagem a métodos de ensino que contemplem uma diversidade de alunos.

Conforme os escritos dos alunos:

- O aluno aprende quando vê em prática o que foi dito em aula teórica. Por exemplo, com o uso de vídeos, imagens, maquetes e exercitando a teoria. (A30) 
- Acredito que o aluno possa aprender através do uso de várias atividades práticas, com uso de imagens, filmes e, principalmente através de discussões. (A12) - Acredito que existem diversas formas, maneiras, modos no qual o aluno adquire o aprendizado. Desde um simples jogo, uma brincadeira, uma leitura, um teatro, uma saída de campo, existem várias formas de aprendizagem. (A48)

Ainda que, o conceito de aprendizagem no início da formação do ser professor, indique falta de clareza teórica, confundindo muitas vezes, o aprender com o ensinar, os licenciados apontam à responsabilidade do professor ao ato de ensinar e de aprender, não os distinguindo, mesmo que esses se complementem em cada sala de aula, em cada contexto educativo, em cada momento do desenvolvimento.

Nesse sentido da diversidade de conceitos e conhecimentos construídos acerca do processo de aprendizagem, justifica-se a sequência de este estudo, como prática pedagógica, não só na formação inicial de professor, bem como nas oportunidades destacadas de formação continuada, de modo que a formação docente seja continua para adentrar as especificidades dos diferentes alunos e suas diversidades, na escola do século XXI, num processo de educação docente continua. "A educação continuada pode ser o diferencial na vida de professores, quando esta proporcionar formação pessoal" (ANTUNES, 2016, p. 85).

\section{Considerações reflexivas}

Afirma-se: o sujeito aprende muito além do espaço educativo institucionalizado, a partir de qualquer contexto social, a qualquer tempo de vida, em qualquer momento do desenvolvimento. Especialmente nos dias de hoje, com tantas informações disponíveis, além da velocidade de informações que são oportunizadas ao indivíduo, o papel do professor é de mediador do conhecimento, assumindo a importante ação de auxiliaria seu aluno às possibilidades de aprendizados pessoais ao longo da vida. Destaca-se que, muito embora, o aprender, seja processo individual no desenvolvimento humano, no sentido da internalização dos conhecimentos adquiridos, muitos outros processos e conceitos estão atrelados a eficácia do processo de aprendizagem e da eficiência do processo de ensino. Nesse contexto, Bernardi (2014, p. 173) enfatiza que "se a criança não aprende a culpa não é somente dela, com certeza a escola, a família e a sociedade possuem uma grande parcela desse fardo pesado da não aprendizagem".

A pesquisa revelou que os alunos quando questionados sobre: como acreditam que o ser humano aprende, em sua maioria, inicialmente, apontam dúvidas em relação ao processo de aprender e atrelam esse, ao método de trabalho do professor, ou seja, ao processo de ensinar. Ainda, indicam a aprendizagem no contexto educativo, nas interações e além dessas, em seus significados pessoais. Já os professores entrevistados, em grande número, destacam a motivação humana, entre outros indicativos, como fator fundamental no aprendizado de seus alunos, mas, sobretudo, também apontam que o processo de aprendizagem depende do método de ensino e, ainda em algumas respostas não é possível identificar as concepções de aprendizagem, pela diversidade de conceitos confusos, no que tange aos processos do aprender.

Alerta-se que este estudo, necessita se constituir, paulatinamente, uma proposta de ensino, na educação superior, quando dos cursos de formação de professores, de modo a oportunizar a estes alunos, momentos reflexivos para uma real aprendizagem e positivo entendimento quanto as suas responsabilidades de ensino, objetivando futuras docências mais condizentes com as intenções, necessidades e realidades dos futuros discentes. Especialmente, quando se vislumbra processos de aprendizagem eficientes para processos de ensino eficazes.

\section{Referências}

Antunes, Denise Dalpiaz. (2016). Oficinas Pedagógicas Cooperativas: a Motivação docente na formação continuada. Curitiba: Editora CRV.

Bardin, Laurence. (2004). Análise de Conteúdo. Lisboa: edições 70.

Bernardi, J. (2014). Discalculia. O que é? Como intervir? Jundiaí: Paco Editorial.

Freire, P. (1996). Pedagogia da autonomia: saberes necessários à prática educativa. São Paulo: Paz e Terra.

Loughran, J. (2009). A construção do conhecimento e o aprender e ensinar sobre o ensino. En M.A. Flores \& A.M.V. Simão (Ed). Aprendizagem e desenvolvimento profissional de profesores: contextos e perspectivas. (17-37). Ramada: Edições Pedago.

Morin, E. (2011). Os sete saberes necessários à educação do futuro. São Paulo: Cortez; Brasília, DF: Unesco, 2011.

Nóvoa, A. (1995). Formação de Professores e Profissão Docente. En: NÓVOA, A.(Org.). Os professores e sua formação. Lisboa: Dom Quixote.

Sopelsa1, O. \& Gazzóla2, L. \& Detoni3, M. Z. (Eds.) (2009). A constituição dos saberes docentes no ensino da matemática: desafios do ensino e da aprendizagem. (pp. 1418-1430) Disponível em http://www.pucpr.br/eventos/educere/educere2009/ana is/pdf/2911_1179.pdf

Sopelsa, O. (2000). Dificuldades de aprendizagem: resposta em um atelier pedagógico. Porto Alegre: EDIPUCRS.

Spitzer, M. (2007). Aprendizagem. Neurociências e a escolA da vida. Lisboa: Climepsi Editores.

Tardif, M. (2012). Saberes docentes e formação profissional. Petrópolis: Vozes.

Tardif, M. \& Lessard, C. (2011). O trabalho docente: elementos para uma teoria da docência como profissão de interações humanas. Petrópolis: Vozes.

Vygotsky, L. S. (2003). Psicologia pedagógica. Porto Alegre: ARTMED.

Vygotsky, L. S. (2002). A formação social da mente. São Paulo: Martins Fontes. 